\title{
Complete Information Multi-players Dynamic Game of Visitor Education Intervention in Tourism Destination
}

\author{
Dongping $\mathrm{Wei}^{1,2}$, Shouwen Wen ${ }^{3, *}$ \\ ${ }^{1}$ Math and Physics Department, Shenzhen Polytechnic, Shenzhen, 518055; \\ ${ }^{2}$ School of Management, Shanghai University, Shanghai, 200444, China; \\ ${ }^{3}$ School of Management, Shenzhen Polytechnic, Shenzhen, 518055, China; \\ E-mail: ${ }^{1}$ wdp@szpt.edu.cn and ${ }^{2}$ wsw@ szpt.edu.cn \\ *Corresponding author. E-mail address: wsw@ szpt.edu.cn \\ Author 1 and 2 with equal contributions
}

\begin{abstract}
The three stages complete information multi-players dynamic game between visitors, local governments and parks managers is proposed in this paper to solve the significant problem about the investment on the visitor education. The game reveals that the government should set up induction fund to lead the parks and tourism companies invest money on visitor education before the Nash Equilibrium state of the game is reached. The win-win-win situation of the government, parks and visitors can be obtained when the positive interaction mechanism of government leading, tourism enterprise implementing and tourist participating is established.
\end{abstract}

Keywords-visitor education; multi-players dynamic games; complete information game.

\section{INTRODUCTION}

The number of domestic tourists reaches 2.9 billion in China in 2012.The negative impacts to the natural ecological environment is introduced by the enormous tourists quickly [1]. The tourism education activities are originated in America. In 1979, the wilderness specialist Jim Bradley proposed a tourism education programme to reduce the negative impacts to Nature Reserve areas [2].In the 1990s, the related department of the United States and Non-Profit Organization designed and promoted a Leave No Trace [3] programme together. China also attaches importance to visitor education in fact. The contents, patterns and routes of visitor education has been studied and practiced fruitfully, but the complete theoretical system, practice pattern, dynamic mechanism, and share responsibility for the education cost are the bottleneck problems. In fact, visitor education intervention is a complex system, Wei,D. and Wen,S. proposed an ordinary differential equation and stochastic Dynamics to study the efficacy of the visitor education intervention [4,5].No all of the stakeholders are willing to input resources to visitor education because of their own benefit, because some tourism resources are not pure public goods. It is the three stages complete information multi-players dynamic game between visitors, local governments and parks managers [6].
It is interesting to apply game theory to study the cost share of visitor education.

\section{NOTATIONS}

$e_{1}$ :The unit cost of behavior intervening

$e_{2}$ :The unit cost of knowledge services

$x_{1}$ : The visitors participation level of behaviors intervention

$x_{2}$ :The visitors' participation level

$u_{1}\left(x_{1} e_{1}\right)$ :The utility function of visitor satisfaction $e_{1}$

$u_{2}\left(x_{2} e_{2}\right)$ :The visitors' satisfaction increment due to knowledge services

$g\left(x_{1} e_{1}\right)$ :The negative utility function

$c$ :The cost of basic services providing by parks

$u(c)$ :The visitors' satisfaction of the basic services

$a$ :the ticket price of park

\section{MUlTI-PLAYERS DYNAMIC GAME OF VISITOR EDUCATION}

The first primary missions of visitor education is intervening the visitors' behaviors base on the aims of parks' management, hereinafter referred to as 'behaviors intervening'. The second primary missions is spreading or sharing knowledge of parks, hereinafter referred to as 'knowledge services'. The total cost of visitor education is $e=\sum_{i=1}^{2} e_{i}$. The utility function of visitor satisfaction is defined as $u_{1}\left(x_{1} e_{1}\right)$. Visitors can choose the participation level according their own need. However, there is negative utility for minority visitors when they reduce uncivilized behaviours. Hence, the utility function of visitors can be denoted as following

$$
U\left(x_{1}, x_{2}\right)=u(c)+\sum_{i=1}^{2} u_{i}\left(x_{i} e_{i}\right)-g\left(x_{1} e_{1}\right)-f(a)
$$


where $a$ is the ticket price of park. The visitors' satisfaction does not decrease when the ticket is priced at reasonable range, otherwise the satisfaction decreases. The tourist quantity increases when visitors' satisfaction increases. The function of tourist quantity can be described as following

$$
N=N\left(U\left(x_{1}, x_{2}\right)\right)
$$

Government collects $t$ taxes on each ticket. Government pays $\alpha$ percentages of the total cost of visitor education. Then the earnings of government is

$$
R_{G}=(t-a e) N\left(U\left(x_{1}, x_{2}\right)\right)
$$

Parks can save a part of resource maintenance and clean-keeping cost by the behaviour intervention. The cost saving can be denoted as $\varphi\left(x_{1} e_{1}\right)$.The knowledge services can save a part of market promotion cost. The part of cost saving is denoted as $\phi\left(x_{2} e_{2}\right)$.So the total incomes of park with $N$ tourists in a certain accounting cycle can be calculated as following

$$
R=\left(a-c-(1-a) \sum_{i=1}^{2} e_{i}+\varphi\left(x_{1} e_{1}\right)+\phi\left(x_{2} e_{2}\right)+\varepsilon-t\right) N\left(u\left(x_{1}, x_{2}\right)\right)
$$

where $1-a$ is the ratio of visitor education cost invested by the park.

In fact, Government-Park-Visitor three Stage Multiplayers Dynamic Game $G\left(S_{1}{ }^{m}, S_{2}{ }^{n}, S_{3}{ }^{k}, R_{G}, R, U\right)$ can be expressed as the following optimization problem: $\max \left\{R_{G}\left(\alpha, t, e_{1}, e_{2}, x_{1}, x_{2}\right), R\left(\alpha, t, e_{1}, e_{2}, x_{1}, x_{2}\right), U\left(\alpha, t, e_{1}, e_{2}, x_{1}, x_{2}\right)\right\}$ s.t.

$$
\begin{aligned}
& S_{1}{ }^{m}=\left\{\alpha \in R^{m}, m=2\right\} \\
& S_{2}{ }^{n}=\left\{e \in R^{n}, n=2\right\} \\
& S_{3}{ }^{k}=\left\{x \in R^{k}, k=2,0 \leq x_{i} \leq 1\right\}
\end{aligned}
$$

\section{SOLUTIONS}

The Backwards Induction is the best method to solve the problem [6].In the third stage of Government-Park-Visitor three Stage Multi-players Dynamic Game, visitors choose the optimal participation level as following

$$
\begin{gathered}
\frac{\partial U\left(\alpha, t, e_{1}, e_{2}, x_{1}, x_{2}\right)}{\partial x_{1}}=u_{1}^{\prime}\left(x_{1}^{*} e_{1}^{*}\right)-g^{\prime}\left(x_{1}^{*} e_{1}^{*}\right)=0 \\
\frac{\partial U\left(a, t, e_{1}, e_{2}, x_{1}, x_{2}\right)}{\partial x_{2}}=u_{2}^{\prime}\left(x_{2}^{*} e_{2}^{*}\right)=0
\end{gathered}
$$

It can be seen from Eq.(6) that visitors choose the optimal participation level $x_{1}{ }^{*}$ in the condition that marginal positive and negative utility of the behaviour intervention are equal. Eq.(7) indicates that visitors choose the optimal knowledge services participation level $x_{2}{ }^{*}$ to gain the maximum satisfaction level $u_{2}\left(x_{2}{ }^{*} e_{2}{ }^{*}\right)$.

In the second stage of Government-Park-Visitor three Stage Multi-players Dynamic Game
$G\left(S_{1}{ }^{m}, S_{2}{ }^{n}, S_{3}{ }^{k}, R_{G}, R, U\right)$, park managers should choose the optimal visitor education investment $\left(e_{1}^{*}, e_{2}^{*}\right)$ in order to gain the maximum earnings. It can obtain the optimal visitors' participation strategy as following

$$
\frac{\partial \varphi\left(x_{1}^{*} e_{1}^{*}\right)}{\partial e_{1}^{*}}=\frac{\partial \phi\left(x_{2}^{*} e_{2}^{*}\right)}{\partial e_{2}{ }^{*}}=(1-\alpha)
$$

The park's optimal investment strategy on visitor education should satisfy that the marginal return of investment on the behaviour intervention equal to the marginal return of investment on the knowledge services.

Backward to the first stage of the game, the government should choose an optimal strategy as following

$$
\frac{\partial \varphi\left(x_{1}^{*} e_{1}^{*}\right)}{\partial e_{1}^{*}}=\frac{\partial \phi\left(x_{2}{ }^{*} e_{2}^{*}\right)}{\partial e_{2}{ }^{*}}
$$

And it can derive from $\frac{\partial \varphi\left(x_{1}{ }^{*} e_{1}^{*}\right)}{\partial e_{1}{ }^{*}}=\frac{\partial \phi\left(x_{2}{ }^{*} e_{2}^{*}\right)}{\partial e_{2}{ }^{*}}=(1-\alpha)$ that $\alpha=0 . \alpha=0$ means that the government does not need to invest any visitor education fund when the multi-players game achieves the Nah Equilibrium state. The government can get the maximum profit at this moment. It can see from the equation $\frac{\partial \varphi\left(x_{1}{ }^{*} e_{1}^{*}\right)}{\partial e_{1}{ }^{*}}=\frac{\partial \phi\left(x_{2}{ }^{*} e_{2}^{*}\right)}{\partial e_{2}{ }^{*}}=(1-\alpha) \quad$ that $\alpha \neq 0$ and $\alpha>0$ when Government-Park-Visitor three Stage Multi-players Dynamic Game $G\left(S_{1}{ }^{m}, S_{2}{ }^{n}, S_{3}{ }^{k}, R_{G}, R, U\right)$ does not achieve the Nash Equilibrium state. The government should invest a lot of fund to induce or support the park to develop visitor education. The Nash Equilibrium solution of the game $G\left(S_{1}{ }^{m}, S_{2}{ }^{n}, S_{3}{ }^{k}, R_{G}, R, U\right)$ can be obtained by the Eq.(6),(7),(8) and (9). And the win-win-win situation of the government, parks and visitors appears on the Nash Equilibrium state of the game. The triple sides gain the maximum benefit simultaneously.

\section{CONCLUSIONS}

When the visitor education system in the tourism market does not established and there are no other external factors to push the establishment, visitor education can only gain the equilibrium in lower level. In that case, the government should set up induction fund to lead the parks and tourism companies invest money on visitor education, because financial fund has the leverage and amplification effect. When visitor education develops to a certain stage with the help of government induction fund, it can run autonomously without the external factors. And the Game $G\left(S_{1}{ }^{m}, S_{2}{ }^{n}, S_{3}{ }^{k}, R_{G}, R, U\right)$ can reach Nash Equilibrium state in the autonomous running stage. 


\section{ACKNOWLEDGEMENTS}

This work is supported by National Science Fund of China(Grant No.71272177/G020902, Grant No.31100958, Grant No. 11101434) and Social Science Foundation of Guangdong(Grant No.GD13CGL16) and Youth Innovation fund of Shenzhen polytechnic(Grant No. 601422K35018) and the Project of Higher Vocational Education Research Society of China (Grant No.GZYLX1213345) and Shenzhen Education Society (Grant No.XH021). And the authors would like to thank the editor and an anonymous referee for their helpful comments on the manuscript.

\section{REFERENCES}

[1] Shouwen,Wen.Research on the Educational Intervention of Visitors in Ecotourism Destinations,Beijing: China Travel \& Tourism Press,pp.11-120,2011.
[2] James R. Pfafflin, Edward N. Ziegler. Encyclopedia of Environmental Science and Engineering,New York: CRC Press, pp26-189,2006.

[3] Marion J L, Reid S E. Minimising visitor impacts to protected areas: The efficacy of low impact education programme, Journal of Sustainable Tourism, 2007, 15(1): 5-27.

[4] Wei D, Wen S, Chen Y, et al; The Stochastic Dynamics for Ecological Tourism System with Visitor Educational Intervention, Mathematical Problems in Engineering, pp.1-9, 2013.

[5] Shouwen wen, Donping wei, The triple-parameters stochastic dynamics of ecological tourism system, Journal of Chemical and Pharmaceutical Research, 2014, pp.715-720.

[6] Shi-yu Xie .Economic Game Theory, Shanghai:Fudian University Press,pp.146-165,2006.

[7] Zhangwei Ying. Game theory and information economic. Shanghai peoples publishing house,pp.96-100,2004. 